\title{
Rabaska
}

Revue d'ethnologie de l'Amérique française

\section{Productions Littorale}

\section{Petronella van Dijk}

Volume 8, 2010

URI : https://id.erudit.org/iderudit/045304ar

DOI : https://doi.org/10.7202/045304ar

Aller au sommaire du numéro

Éditeur(s)

Société québécoise d'ethnologie

ISSN

1703-7433 (imprimé)

1916-7350 (numérique)

Découvrir la revue

Citer ce document

van Dijk, P. (2010). Productions Littorale. Rabaska, 8, 309-310.

https://doi.org/10.7202/045304ar d'utilisation que vous pouvez consulter en ligne.

https://apropos.erudit.org/fr/usagers/politique-dutilisation/ 
- L'ÉCONOMUSÉE de la pomiculture-Cidres et vergers Pedneault a gagné la coupe Grand Or pour Le Glacier (cidre de glace) et l'argent pour la Prunelle (boisson à base de prune) et la Mistelle de pommes à la Coupe des nations 2010.

Le réseau ÉconomuséE continue de se développer avec des projets notamment en Colombie-Britannique et en Saskatchewan, et une deuxième phase d'implantation en Europe du Nord.

Gabrielle NAMmour

\section{Productions Littorale}

138, rue Wellington Nord

Salle 202

Sherbrooke (Québec)

J1H 5C5

Téléphone : (819) 566-6996

Télécopieur : (819) 780-8972

Courriel : info@productionslittorale.com

Toile : www.productionslittorale.com

\section{Productions Littorale prend position...}

En octobre 2009, Productions Littorale présentait la $17^{\mathrm{e}}$ édition du festival du conte «Les jours sont contés en Estrie » sous le thème Les Tisseurs de parole. Une trentaine d'artistes d'Europe et du Québec se partageaient les lieux et tissaient, dans toute la région et dans la ville de Sherbrooke même, une vaste courtepointe faites de motifs de rêves et d'espoir. Si le festival demeure notre événement-phare, 2009 fut une année marquante sur le plan de la réflexion puisque nous avons mis sur pied une Rencontre internationale sur le conte, témoin du temps, observateur du présent. Pour cette occasion, nous avions deux invités de renommée : Marc Aubaret, ethnologue et directeur du Centre méditerranéen de littérature orale à Alès (France) était notre invité d'honneur et il a présidé les tables rondes présentées les 17 et 18 octobre, après avoir donné une conférence d'ouverture le vendredi 16 octobre sur l'Histoire de la littérature orale. La deuxième invitée, la marraine de l'événement, était la cinéaste, actrice et scénariste Micheline Lanctôt, bien connue du milieu culturel québécois. Nos deux invités d'honneur étaient bien entourés puisqu'une dizaine de conteurs étaient présents : Mike Burns (Irlande), Jihad Darwiche (Liban), Regina Machado (Brésil), Fabienne Der Stépanian (France), Joujou Turenne (Haïti), Regina Sommer (Allemagne), Michel Hindenoch (France) et puis, du Canada, Dan Yashinsky, et du Québec : Jacques Falquet, Robert Bouthillier, Christian-Marie Pons, Vivian Labrie, Flavie Dufour, Marc-André Caron, Éric Gauthier, Christiane Lahaie, Marie Lupien-Durocher et Lynda Dion. 
Des discussions animées ont conduit un comité à se réunir en France en juin 2010 pour entamer un travail précis de mise en place d'une " poétique du conte », autrement dit d'un appareil critique qui aidera toutes les personnes et instances intéressées à mieux comprendre cet art et à en évaluer les tenants et les aboutissants. Ce travail de réflexion fera l'objet d'une publication aux Éditions Planète rebelle en janvier 2011, et le lancement se fera en présence de Marc Aubaret à Montréal dans le cadre des activités de la petite mais dynamique maison d'édition montréalaise.

Parallèlement à ce double travail événementiel, tout au long de l'année, Productions Littorale propose au public estrien de se familiariser avec le conte par sa programmation régulière qui est disponible sur le site www.productionslittorale.com et par des ateliers d'initiation ou de stages de perfectionnement pour les conteurs. Une planification stratégique doublée d'un travail de consultation plus pointu avec la firme Absolu Marketing nous permet d'orienter de manière plus pertinente nos actions, bien que nous devions malheureusement toujours faire le constat d'une grande méconnaissance de ce « vieil art » qu'est le conte, de son histoire fabuleuse, de sa richesse patrimoniale. Loin des claviers fulgurants et des internautes obsessifs, nous menons notre barque de bois précieux vers des rivages où le temps existe encore et où l'humain est resté... humain.

Toutes ces analyses, discussions, réflexions et autres cogitations ne nous empêchent pas de mener une double, voire une triple vie puisque nous fréquentons bien sûr aussi d'autres festivals, d'autres événements et que nous siégeons au conseil d'administration du Regroupement du conte au Québec qui mène, à sa manière, une campagne de valorisation de la parole conteuse dans toute la province et organise toutes sortes d'activités tout au long de l'année (des formations, des spectacles, un colloque, etc.). Nous participons encore, en tant que membres, à l'événement annuel des Storytellers du Canada / Conteurs du Canada qui, bien que se déplaçant de province en province chaque année, a réussi à réunir cette année, sur le lointain rocher de TerreNeuve, pas moins de 160 personnes passionnées venues de partout au pays. Le « vieil art » reste méconnu, mais il n'a pas dit son dernier mot !

Petronella Van DiJK 